\title{
A Eleição de Foro \\ Segundo a Nova Lei Suíça \\ Sobre o Direito Internacional Privado \\ de 18 de Dezembro de 1987*
}

\section{ALFRED E. VON OVERBECK}

Professor Emérito da Universidade de Friburgo, Suíça e

Ex-Diretor do Instituto Suíço de Direito Comparado, Lausanne

\section{INTRODUÇão}

0 presente artigo é essencialmente consagrado a um comentário ao artigo $5^{\circ}$ da lei Federal Suiça de 18 de dezembro de 1987, norma de direito internacional privado (LDIP) que entrou em vigor em 10 de janeiro de 1989. ${ }^{1}$ Todavia importa assinalar que em 10 de janeiro de 1992 entrou em vigor a Convenção de Lugano concernente à competência judiciária e à execução das decisões em matéria civil e comercial, de 16 de setembro de 1988, isto nas ligações entre a França, os Paises Baixos e a Suiça. Este instrumento, destinado a ser ratificado por todos os membros da Comunidade Européia e da Associaçāo Européia de Livre Comércio visa estender a todos os Estados o sistema da Convenção de Bruxelas de 1968/1978/1989. Nas relações com os Estados contratantes e para as matérias regidas por esta convenção, 0 art. $5^{\circ}$ da LDIP tornar-se-á sem objeto, enquanto continuará reger as ligaçōes da Suiça com os outros Estados. Ressaltemos as principais diferenças entre as Convenções de Bruxelas e de Lugano e o sistema da LDIP. ${ }^{2}$

A importância das cláusulas atributivas de competência, ou cláusulas de eleição de foro, ou, ainda, cláusulas de prorrogação de foro, em Direito Internacional Privado, não necessita mais ser demonstrada; o mesmo ocorrendo com os problemas dela decorrentes, traduzidos por um número relativamente considerável de decisões judiciais. ${ }^{3}$

Diversos motivos inspiram estas cláusulas. Comumente, elas figuram nos contratos pré-estabelecidos (contratos de adesão) e têm por objetivo concentrar o maior número de processos possiveis na sede de uma empresa. Em outros casos, contudo, elas correspondem aos interesses de duas partes que querem, por exemplo, submeter-se a uma jurisdição neutra. Os motivos relativos à execução de um eventual julgamento podem ocasionalmente desempenhar seu papel, como no exemplo dado por M. Schutze:4 em um contrato entre um alemão e um finlandês a execução, em outro pais, do julgamento realizado no país de um dos contratantes é duvidosa; por outro lado, os julgamentos suecos ou dinamarqueses podem ser executados tanto na Alemanha Federal quanto na Fintândia, donde um certo interesse a escolha de um foro em de um certo interesse na escolha de um foro em um destes paises.

Deixaremos de lado a submissão voluntária a um foro incompetente em absoluto, que é, em geral, admitida nos casos em que ocorre uma prorrogação.

Para a Suica, a entrada em vigor da Lei Federal sobre o Direito Internacional Privado, de 18 de dezembro de 1987, (LDIP) constitui um passo essencial. Regulamentando a eleição de foro no plano federal, em matéria internacional, ela subtraiu esta questão das numerosas regras

"Texto enviado ao Congresso "Contratos Internacionais e Mercosul", setembro 1992. Organização e Revisões pela Professora Claudia Lima Marques, Faculdade de Direito/UFRGS. 
cantonais* que permaneceram, contudo, em vigor nos casos intercantonais e mesmo em matê ria internacional, quando são mais liberais que a lei federal.

Todavia, note-se que os principios jurisprudenciais guardam a sua importância para tudo denclais guardam a sua importancla para tudo aquilo que náo è regulamentado pela nova le isto é, sobretudo para a formação de eleições de foro, por oposição à sua admissibilidade e a seus efeitos processuais, que estão regulados na nov lei.

Depois, o que é notório, mas que é dito ex pressamente no art. 10, alinea 2 da LDIP, as regras dos tratados em vigor prevalecem na matéria. Tratam-se de disposiçōes nos tratados bilaterais sobre o reconhecimento e a execução, das quais a mais importante é, sem dúvida, art. 3 da Convenção Franco-Suiça de 15 de junho de 1869 , que assim dispõe:

"Em caso de eleição de domicílio em lugar diverso do daquele do domicilio do defensor os juízes do lugar do domicilio eleito serão os únicos competentes para conhecer das dificuldades as quais a execução do contrat poderá dar lugar."

Os Tribunais suiços e franceses interpretaram constantemente a cláusula como aquela que possibilita um acordo entre as partes Para Suiça isto significa particularmente que, no quadro da Convenção Franco-suiça, as exigências para a validade da cláusula de eleição de for são menos rigorosas que no direito comum. Tribunal Federal tem julgado que, mesmo no quadro do tratado, era uma questão de Direito Cantonal saber se o juiz designado devia aceitar sua competência; ele poderia, por exemplo recusá-la se entendesse que não havia vinculo determinante de foro A LDIP regula, igualmente, este último ponto.

Enfim, os Estados da Comunidade Européia e aqueles da Associação Européia de Livre Comércio concluiram um tratado paralelo à Convenção de Bruxelas no que toca à competência judiciária e à execução das decisões em matéria civil e comercial (texto modificado em 9 de outubro de 1978). Quando esta Convenção for retificada, substituirá, evidentemente, no seu dominio de aplicação, tanto as regras de LDIP

*A Suiça organiza-se em cantōes, estados da Confederação. (N. do T.) quanto as dos tratados com os Estados do Mercado Comum (Convenção de Lugano de 16 de setembro de 1988).

\section{I - GÊNESE E COMENTÁRIO DO ARTIGO 50 DE LEI FEDERAL DE 18 DE DEZEMBRO DE 1987}

Convém explicar como se chegou ao texto do art. $5^{\circ}$ e quais são os problemas que ele resolve expressamente. Examinaremos, em seguida, o reconhecimento de julgamentos estrangeiros pronunciados no foro contratual ou, ao contrário, a despeito de uma eleição de foro.

Como todas as disposiçōes legais, este texto foi elaborado por uma subcomissão da Comissão de "experts", sendo depois submetido à Comissão de Presidentes que o modificou profundamente. Outras modificações tiveram lugar no curso da discussão parlamentar, particularmene no que diz respeito à terceira alinea.

O artigo nono do texto da Subcomissão IV, de dezembro de 1984, tinha o seguinte teor:

"1. Salvo disposição contrária, as partes podem acordar, na forma escrita ou, em matéria comercial, por outros meios usuais como o telegrama ou telex, que buscarão um outro juiz que não o previsto pela lei para conhecer dos conflitos nascidos ou a nascer por ocasião de um relatório de direito determinado, desde que o foro escolhido tenha uma ligação efetiva com o objeto de litigio ou com uma das partes em causa.

2. Se uma tal convenção atributiva de jurisdição foi estipulada somente em favor de uma das partes, essa conserva o direito de levar sua ação ao juiz competente nos termos da presente lei.

3. Salvo se se tratar de foros exclusivos, a parte que instaura o processo sem fazer reserva reconhece a competência do juiz demandado."

Retomemos agora os diversos elementos do art. $5^{\circ}$ da LDIP, cujo texto è o seguinte:

"Art. 50

IV - Eleição de foro

1. Em matéria patrimonial, as partes podem convencionar sobre o tribunal chamado a resolver um conflito nascido ou a nascer por ocasião de un por minada. A convenção pode ser feita por es- crito, por telegrama, telex, fax ou qualquer outro meio de comunicação que permita estabelecer a prova por um texto. Salvo estipulação em contrário, a eleição de foro é exclusiva.

2. A eleição de foro fica sem efeito se ela priva, de forma abusiva, uma das partes da proteção que lhe assegura um foro previsto pelo Direito Suiço.

3. O tribunal eleito não pode declinar de sua competência.

a. Se uma parte é domiciliada, tem sua residência habitual ou um estabelecimento no cantão onde ele tem sede, ou

b. Se, em virtude da presente lei, o Direito suiço é aplicável ao litigio."

\section{Alínea Primeira: a Admissibilidade e a} Forma de Eleição de Foro

\section{a) A Eleição de Foro é Admissível em} Matéria Patrimonial

$\mathrm{O}$ anteprojeto da subcomissão não previa, $\mathrm{n}$ alinea primeira, o limite quanto à matéria. Este somente reservava os foros exclusivos no que concerne à aceitação tácita de um foro em si competente (alinea $3^{\mathrm{a}}$ ), mas a intenção, sem dúvida, era fazê-los prevalecer também sobre a eleição de foro.

A comissão de "experts" discutiu longament a questão de saber como reservar os foros que não podem ser derrogados. Asseverou-se que os termos "foro imperativo" ou "foro exclusivo" sua contrapartida em alemão dão lugar a multas confusões. A terminologia exata parecia ser a seguinte: um foro imperativo é um foro que não pode ser derrogado pelas partes, mas sem que uma ação a um foro estrangeiro seja excluida. Assim, por exemplo, os foros em matéria de divórcio fixados pela LDIP são imperativos; não se pode ai derrogar por uma eleição de foro; em compensação, não são exclusivos já que se reconhece, também, uma decisão tomada no país estrangeiro do domicilio ou da nacionalidade de um dos cônjuges (arts. 59, 60 e 65 da LDIP) Em compensação, exceto para algumas situaçoes particulares, o foro do domicílio do defensor é exclusivo na Suica, em virtude do art 59 exa mada em foro estrangeiro não é reconhecida. Em compensação, ele não é imperativo, as partes podem tentar derrogá-lo.

Há, por vezes, foros que são imperativos e exclusivos, como é o caso do foro do art. 97 da Lei Suiça para ações reais imobiliárias relativas a imóveis situados na Suiça. ${ }^{7}$

A essas dificuldades de semântica somamse problemas fundamentais: freqüentemente é dificil saber quais são considerados como imperativos ou exclusivos; isto ocasiona um problema tanto na aplicação de convenções bilaterais, reservando a competência exclusiva de uma das partes, quanto no Direito Cantonal Suiço.

A comissão de "experts" resolveu o problema abandonando a idéia de uma reserva de foros exclusivos ou imperativos para a prorrogação das matérias patrimoniais. Por outro lado, engloba-se tanto o direito das obrigações quanto, por exemplo, o direito de sucessões e o direito dos regimes matrimoniais.

Para certas matérias patrimoniais, a eleição de foro é, entretanto, excluida ou restringida pelas disposições da parte especial que não se pode perder de vista. Assim, sem que seja dito expressamente, a prorrogação é excluida para as açōes reais imobiliárias (art. 97), sendo que, nos casos de ação por responsabilidade depois da emissão de titulos de participacão e de empréstimo (art. 151, al. 3), ela o é expressamente. Por outro lado, um consumidor não pode renunciar de antemão ao foro de seu domicilio ou de sua residência atual (art. 114, al. 2).

Os artigos 226 I e 228 do Código Federal das Obrigaçóes em matéria de contratos de venda a prazo e com pagamento antecipado e 0 art. 30 da Lei Federal sobre a fiscalização das garantias, de 23 de junho de 1978, contêm, igualmente, restrições que se aplicam em matéria internacional. Em compensação, a LDIP não prevê restriçōes em matéria de obrigações alimentares ou de contratos de trabalho. ${ }^{8}$

\section{b) As Partes Podem Reconhecer a} Competência do Tribunal

$\mathrm{O}$ anteprojeto da Subcomissão falava em um outro juiz que não o previsto pela lei". Ele apenas considerava a substituição do juiz regularmente competente por um outro juiz suico. Este pexto deava emerto um ponto capital: a possibilidade de derrogar a competência suiça 
em favor de um foro estrangeiro. 0 texto atual engloba diferentemente os dois casos. Num dado momento, pensou-se até em regulá-los separadamente

Quando as partes designarem um foro suiço, a prorrogação será eficaz se as condições de admissibilidade do Direito suiço forem preenchidas e, bem entendido, se ela foi validamente concluida segundo o direito que lhe é aplicável em virtude das regras de conflito em matéria contratual.

A designação do tribunal deve ser suficientemente precisa, não sendo bastante designar-se os tribunais suiços. Em compensação, basta designar os tribunais de um certo lugar; não e necessário mencionar especificamente, por exemplo, o presidente do Tribunal ou o Tribunal de Comércio.

0 tribunal suiço deve considerar uma interdição de prorrogar-se, determinada por um pais estrangeiro que se julga exclusivamente competente para uma certa questão? Pode-se dar o exemplo da competência exclusiva dos tribunais da situação para os bens imóveis, em aplicação do art. 16, Capitulo Primeiro, da Convenção de Bruxelas. Sabe-se que a Corte de Justiça da CEE, em Luxemburgo, em uma decisão fortemente criticada, estabeleceu que esta valia ate mesmo para um apartamento para férias, na Itália, alugado de um nacional alemão a outro Um juiz suiço poderia declarar-se competente, aplicando-se uma prorrogação de foro ocorrida entre o proprietário de uma casa para férias na Itália, suiço, domiciliado na Suiça, e seu locatário, um suiço, domiciliado nos paises baixos? Não se vê em virtude de que principio o juiz suiço respeitaria o caráter exclusivo e imperativo do foro da situação. A condição, certamente, de que a prorrogação fosse válida segundo o direito suiço, ele deveria admitir sua competência. Ver-se-á, mais adiante, qual a sua posição em matéria de reconhecimento e se, ao contrário, o foro exclusivo, segundo 0 art. $16 \mathrm{da}$ Convenção de Bruxelas deveria ser adotado.

$\dot{E}$ de se perguntar, todavia, se o juiz suiço deveria recusar-se a considerar-se competente num caso particular: aquele em que não apenas ele seria incompetente fora da prorrogação, mas também em que transpusesse seus próprios principios em matéria de competência direta a competência indireta de um outro pais. Neste caso, esse último seria exclusivamente competente 10

A professora Kaufmann-Kohler parece admitir tal situação em algumas hipóteses No sistema da LDIP, não cabe mais a transposição da competência direta para a indireta (sistema da "Spiegel-bildlichkeit" e, por outro lado, a LDIP prevê um número reduzido de competências exclusivas. 0 art. 86, al. 2, exclui a competência das autoridades suiças para as questões sucessórias relativas aos imóveis para os quais o Estado do lugar da situação reivindica uma competência exclusiva. A "ratio legis" - evitar as decisōes ineficazes - vale também para que se encontre uma eleicão de foro para tais questóes, a menos, certamente, que a competencia toes, a mes. certamente, que a competencia do Estado da situação não seja exclusivo nem imperativo, ou seja, que ele possa ser derrogado por convenção. 0 mesmo raciocinio deve valer para os direitos reais relativos a imóveis situados no exterior; a LDIP não prevê competência para estas questōes. Aqui, poder-se-ia sustentar, com bons argumentos, que o juiz suiço deveria levar em consideração a ineficácia da derrogação no pais principalmente interessado e recusar-se a decidir.

As condições do art. $5^{\circ}$, alinea primeira, devem também ser reunidas para que haja efeito derrogatório de uma competência legal suiça em favor de um tribunal. Este caso suscita problemas suplentares. $O$ efeito derrogatório desaparece, certamente, se o tribunal estrangeiro designado declinou de sua competência. Em tais casos, o juiz suiço, competente segundo a LDIP na falta de eleição de foro, deve poder decidir. Poder-se-ia pensar em regular este caso invocando o foro de necessidade do art. $3^{\circ}$ da LDIP, na nossa opinião, é a competência normal que reina.

Mas o que ocorre se uma parte se dirige a um tribunal suiço reclamando que a prorrogação não é admitida segundo o Direito estrangei ro? Cremos que não há dúvida de que o tribunal estrangeiro eleito declinaria de sua competência, por exemplo, porque a seus olhos a matéria não é uma daquelas onde uma eleição de foro è possivel, o juiz suiço normalmente competente deveria investir-se. ${ }^{12}$ c) A Eleição de Foro Deve Relacionar-se Com Um Conflito Nascido ou Por Nascer na Ocasião de Um Caso Determinado

Esta condição encontra-se, igualmente, no art. 17 da Convenção de Bruxelas. Ela se explica pela preocupação de não se ver uma parte ligar-se a litigios cuja natureza não possa conhecer. Pode-se ressaltar, a esse propósito, que nas Comissōes Parlamentares na Suiça a questão foi levantada a fim de se saber se os acionistas estavam ligados por uma eleição de foro contida no estatuto de uma sociedade anônima. $A$ resposta foi negativa. ${ }^{13}$

d) A Forma da Cláusula de Eleição de Foro

A segunda frase da primeira alinea diz respeito à forma e aos meios técnicos pelos quais a convenção das partes pode ser exprimida. Foram enumerados os meios técnicos mais cor rentes sem excluir-se outros. Assim, exprimiuse a opiniāo de que os disquetes de computadores que permitissem estabelecer um texto, poderiam ser suficientes. Exigindo que as partes deriam ser suficientes. Exigindo que as partes empregassem um meio de comunicação que permitisse estabelecer a prova por um texto, a LDIP é mais restritiva que a Convenção de Bruxelas, que se contenta com um acordo verbal confir mado por escrito e por formas admitidas no comércio internacional. ${ }^{14}$

Se as partes, das quais ao menos uma tem seu domicilio no território de um estado contratante, acordam um tribunal ou tribunais de um Estado contratante para conhecer dos debates nascidos ou a nascer por ocasião de um caso de direito determinado, este tribunal ou os tribunais deste Estado são os únicos competentes. Esta convenção atributiva de jurisdição é concluida:

- por escrito ou verbalmente com confirmação escrita, seja;

- sob uma forma que esteja conforme os hábitos que as partes estabeleceram entre elas, seja;

- no comércio internacional, sob uma forma que esteja conforme um uso de que as partes tenham conhecimento ou julguem ter conhecimento e que seja largamente conhecido e regularmente observado nesse tipo de comercio pelas partes, em con- tratos do mesmo tipo, no ramo comercial considerado.

e) A Presunção de Exclusividade de Eleição de Foro

Segundo a terceira frase do art. $5^{0}$, alinea primeira, salvo estipulação em contrário, a eleicão de foro é exclusiva. Esta regra clara põe fim às hesitaçoes da jurisprudência e da doutrina suiças que assinalamos. Ela vale quando um foro foi designado sem outra fixação. Mas, bem entendido, as partes são livres para acordar sua prorrogação, descartando a presunção de exclusividade. Elas podem, assim, criar eleiçoes de foro "capengas" dando a uma das partes, não à outra a escolha entre diversos foros. Isto cria uma certa desigualdade entre as partes que a uma certa desigualdade entre as partes que a te, não é desejável presumir uma cláusula capenga. Ora, é justamente isto que faz 0 art. 17 , alinea 4 da Convenção de Bruxelas e da Convenção de Lugano:

"Se uma convenção atributiva de jurisdi-

ção foi estipulada a favor de apenas uma das partes, esta conserva o direito de escolher qualquer outro tribunal competente em virtude da presente convenção."

Uma critica muito pertinente a essa cláusula, encontra-se no artigo de Christian Kohler. ${ }^{15}$ Este autor relata as incertezas e as dificuldades que a cláusula levantou na jurisprudência de vários paises. É necessário tomar-se como base as circunstâncias objetivamente favoráveis a uma das partes, ou a apreciação subjetiva dos contratantes? E qual o momento determinante? Sem entrar em detalhes, não saberiamos fazer depender de elementos tão incertos a determinação do tribunal que será invocado, já que a segurança é, precisamente, um dos motivos principais da eleição de foro.

Essa disposição produz, aliaas, resultados que nāo podem ser desconsiderados. Na prática, ela conduz a tomar-se, no lugar do foro prorrogado, o foro do domicilio. De acordo com uma opinião um pouco ingênua, que encontramos na doutrina suiça e que certos tribunais alemães adotaram, o fato de ser procurado no seu próprio domicilio constituiria sempre uma vantagem. Ora, isto está longe de ser verdade. Não paremos na esperança de que o julgamento le- 
vado ao foro contratual estrangeiro não possa ser executado; isto não è um interesse juridicamente protegido. Aliás, no quadro da Convenção de Bruxelas, não deve normalmente haver dificuldades para a execução de uma decisão tomada no foro contratual. É também por esta razão que não poderiamos justificar 0 art. 17 alinea 4 da Convenção de Bruxelas, porque necessário permitir à parte - à favor da qual a prorrogação foi feita - agir no foro do domicilio prorrogação foi feita - agir no foro do domicilioa da outra parte, já que a execução da
tomada no foro contratual seria incerta.

tomada no foro contratual seria incerta.
Mas há circunstâncias em que se prefere um tribunal estrangeiro aos juizes locais, de quem se desconfia, ou que se considere um outro tribunal mais eficaz ou mais experiente.

Enfim, não se vê porquê uma parte, hipoteticamente favorecida pela eleição de foro, receberia uma segunda vantagem: a de poder escolher entre o foro eleito e um outro foro. Trataremo da escolha do tribunal na sede da parte que redigiu um contrato de adesão. Se esta escolhe um foro diferente do foro escolhido, não sera certamente por altruísmo, mas porque ai vê uma vantagem no plano do processo ou porque, segundo as regras de conflito, diferentes deste outro foro, uma lei que lhe é mais favorável torna-se aplicável. Em matéria de prazo de prescrição, por exemplo, isto pode distinguir um processo ganho de um perdido!

A Corte das Comunicações Européias, em uma decisão Anterist contra Crédit Lyonnais, de 24 de junho de $1986^{\circ}$, felizmente fez justiça através desta cláusula. Decidiu-se que só o fato do foro do domicilio de uma parte ter sido escolhido não significa que a prorrogação tenha sido feita em favor de uma única parte; é necessário ao contrário, a vontade comum das partes de favorecer a uma delas seja estabelecida. Praticamente, isto não deixa mais muito alcance à disposição. Kohler, seguindo o que os britânicos já fizeram para suas regras "interlocais" propõe suprimir a cláusula na próxima ocasião. ${ }^{16}$ Pode-se lastimar que ela seja mantida na convenção paralela.

A submissão da Comissão de "experts" tinha, sobre este ponto, seguido as sirenes de Bruxelas e, não sem dificuldades, a Comissão dos Presidentes pôde ser persuadida a suprimir esta cláusula.
A idéia do "foro capenga" presumido não foi retomada na discussão parlamentar. Por outro lado, a cláusula de exclusividade foi combatida por certos partidários da supressão da terceira alinea, relativa à obrigação do tribunal eleito de investir-se. Esta solução, que teria novamente livrado a cláusula de prorrogação das incertezas do folclore cantonal, não encontrou apoio.

\section{Alínea 2: As Cláusulas Abusivas}

Introduzindo a alinea 2, a Comissão de "experts" tinha em vista principalmente as cláusulas de prorrogação nos contratos pré-estabelecidos ou contratos de adesão.

Quando da discussão parlamentar, a disposição reencontrou objeções de duas ordens opostas. Para alguns, ela arriscava prejudicar a segurança das demandas, permitindo colocar, demasiadamente seguido, em dúvida a validad da eleição de foro. Outros entendiam que a regra não era necessária, sendo suficiente a disposição geral sobre 0 abuso de direito do art. $2^{\circ}$, alínea 2 do Código Civil suiço. Contrariamente, certos deputados criticaram o fato de que a cláusula se referia apenas à proteção que assegura um foro previsto pela lei suiça; eles quiseram estender a regra também a uma derrogação abusiva de um foro estrangeiro.

O Conselho dos Estados, câmara buscada em primeiro lugar, decidiu cancelar o texto ${ }^{18}$, en quanto que o Conselho Nacional preferiu mantê $10^{19}$ ponto de vista a qual o Conselho dos têlo que o texto tenha sido mantido na Convenção de Lugano.

Observamos, ainda, que a Convenção de Haia sobre os acordos de eleição de foro, de 25 de novembro de 1965 (que não entrou em vigor), permite, no art. 15 o não reconhecimento dos acordos de eleição de foro "se, consideradas as circunstâncias, houver grave inconveniente no caso da cláusula ser julgada pelo tribunal eleito".

O texto da Convenção de Bruxelas não faz alusão às cláusulas abusivas de eleição de foro. Kropholler ${ }^{21}$ desejaria uma tal cláusula ou o desenvolvimento de uma jurisprudência pela corte européia. Ele propõe que não se admita uma prorrogação por duas partes residentes no mesmo pais em favor de um tribunal estrangeiro situado num país com o qual não haja nenhuma ligação. ${ }^{22}$ Pode-se assinalar, a esse propósito, que uma decisão italiana faz prevalecer, num caso semelhante, 0 art. $2^{\circ}$ do Código de Processo Civil Italiano que invalidava a eleição de foro e que, de forma oposta, a decisão de corte de Munique fez valer uma cláusula semelhan te 23 Na Suica consideramos que não se trata de uma materia internacionl, no sentido do art. de uma materia internacional, no sentido do art $1^{\circ}$ da LDIP, embora o direito cantonal seja determinante.

\section{Alínea 3: A Obrigação do Juiz Escolhido de Não Declinar de Sua Competência}

A terceira alinea regulamenta uma questão muito importante. No quadro do Mercado Comum, quando ao menos uma parte é domiciliada no Estado do contrato, 0 art. 17 da Conven ção de Bruxelas e de Lugano não deixam dúvi das; ocorrendo o mesmo segundo o art. 15 da Convenção de Haia sobre os acordos de eleição de foro, de 25 de novembro de 1965.

0 anteprojeto de Subcomissão IV exigia uma ligação efetiva com o objeto do litigio ou com uma das partes em causa. A Comissão dos Presidentes preferiu uma solução mais liberal. opinião mais defendida foi a de que se deveria respeitar a confiança que as partes estrangeiras concederam a certos tribunais suicos e lhes permitir uma prorrogação mesmo a despeito da ligação objetiva com o pais.

Isto conduz à fórmula do projeto do Conselho federal, segundo o qual o tribunal eleito não podia declinar de sua competência se uma par te fosse domiciliada ou tivesse residência habitual ou um estabelecimento na Suiça, ou se, em virtude da Lei de Direito Internacional Privado o Direito suiço fosse aplicável ao litígio. Enten deu-se que o Direito suiço podia ser aplicáve tanto em razão de uma conexão objetiva quanto em virtude da autonomia das partes.

Esta solução, muito liberal, não deixou de provocar objeçōes quando dos debates parlamentares. Fez-se valer, em particular, que ocorrendo a sobrecarga dos tribunais, não se podia obrigá-los a julgar litígios sobre matérias que não tivessem nenhuma relação com sua sede. Também diversas förmulas mais restritivas foram examinadas.
Conselho dos Estados elaborou uma fórmula que permitia aos cantōes limitarem a obrigação de aceitar competência quando ambas as partes não tivessem domicilio, residência habitual ou estabelecimento no cantão do tribunal e, isto, mesmo se o direito suiço fosse aplicável. ${ }^{24}$

Por outro lado, o Conselho Nacional adotou um texto atual que obriga sempre um tribunal a julgar-se competente, quando o direito suíço é aplicável, do mesmo modo que quando uma par te tem seu domicilio, sua residência habitual ou um estabelecimento no cantão da sele do Tribunal. ${ }^{25}$

Ainda nos perguntamos o que se passaria no caso de uma parte ter um domicilio e, portanto um foro na Suiça, mas o tribunal de um outro cantão ter sido designado. Um tal foro, validamente escolhido porque o Direito suiço era aplicável, deveria ceder lugar ao foro legal no cantão do domicilio? Esta restrição foi descartada por diversos motivos, sobretudo por consideraçōes que já descartamos a propósito do "foro um tribunal de comércio experimentado de uma grande cidade antes de pleitear junto ao juiz do domicilio da cidade de uma de-

Percebeu-se, aqui, como em outras ocasiōes, que os federalistas procuravam dar maior espaco ao Direito cantonal, lembrando-se com nostalgia que as questōes de processo são reservadas pela Constituição aos cantōes. No final das contas, o Direito cantonal conservou um espaço, mas ele somente pode intervir caso seja mais favorável à prorrogação do foro que o direito Federal. Com efeito, se nos casos mencionados na alinea 3 o tribunal eleito não pode declinar de sua competềncia, ele não é obrigado a fazê-lo em outros casas. Ele deverá admitir sua competência quando o Direito cantonal o prescreva. Assim, no cantằo de Zurique, a prorrogação também deverá ser aceita se uma das partes for um suiço domiciliado no exterior ou se a prorrogação tratou de um empréstimo por obrigações emitidas em Zurique ${ }^{26}$ Será interessante observar se os cantões, tal como no cantão de Vaud, onde atualmente toda a prorrogação parece ser admitida ${ }^{27}$, embora sem base legal, manterão essa jurisprudência. 
A questão da proteção dos suiços domiciliados no exterior foi ocasionalmente levantada na discussão, mas, enquanto os foros principais ou subsidiảrios fundados na nacionalidade são pre vistos no direito de familia e sucessōes, os sui ços domiciliados no exterior não têm, em matéria de prorrogação, mais direitos que os estrangeiros. Podemos lastimar, mas talvez fosse preferivel preocuparmo-nos com o problema ao invés de procurarmos, a todo preço, deixar um campo de aplicação ao Direito cantonal.

No final das contas, a regulamentação é ainda assim assaz liberal: o só fato de ter provido eleição do foro de uma escolha do Direito suiço obrigará o tribunal designado a investir-se. pouco provável e, em todo caso desaconselhá vel, que as partes designem um foro suiço, na falta de uma escolha simultânea da lei suiça ou do domicilio de uma delas no cantão do tribunal demandado, na esperança de que esse for queira declarar-se competente.

\section{III - QUESTÕES RELATIVAS AO RECONHECIMENTO E À EXECUÇÃO DAS DECISÕES ESTR ANGEIRAS}

Convém sublinhar, em primeiro lugar, que de maneira geral, a LDIP traz um progresso considerável no que toca ao reconhecimento e à execução de decisões estrangeiras provenientes de paises com os quais não há tratados. Nós nos lembraremos que a maior parte dos códigos Cantonais exigem a prova da reciprocidade e que o Tribunal cantonal de "Glavis" decidiu, inclusive, não reconhecer e não executar decisões estrangeiras fora dos tratados.

\section{A Execução das Decisões Tomadas no Foro Contratual Estrangeiro}

De acordo com o art. 26, letra "b" da LDIP, competência indireta das autoridades estrangeiras é dada se, em matéria patrimonial, as par tes se submetem, por uma convenção válida segundo a presente lei, à competência da autoridade que tomou a decisão.

Antes de reconhecer ou permitir a execução tomada por um tribunal eleito no exterior, o juiz suiço examinará se as condiçōes "da present lei", isto é, do art. $5^{\circ}$, estāo presentes e se não há outras restrições a observar, como, por exem- plo, aquela do art. 97 relativa aos imóveis suicos e aquela do art 114 concernente ao contrato do consumidor Em contra mente do qu que se encontra em antigas convençôes, não é necessário examinar se, segundo seu próprio Direito, o tribunal de origem podia investir-se com base na prorrogação. ${ }^{28}$ Não deve, bem entendido, haver outros motivos de recusa do reconhecimento (art. 27)

Mesmo se a prorrogação do foro não tiver efeito segundo o Direito suiço, a decisão estrangeira poderá ser reconhecida de acordo com as regras do Direito suiço sobre a competência indireta, se o tribunal estrangeiro for competente por outro título.

A questão critica é saber se um julgamento realizado com base numa prorrogação de foro que não responde às exigências do art. $5^{\circ}$, em um Estado no qual não existe uma autoridade com competência indireta aos olhos do Direito suiço, pode ser suscetivel de reconhecimento. Em regra, dever-se-á responder negativamente, em outros casos, uma resposta afirmativa parece possivel.

Suponhamos que, conforme as regras suiças de competência indireta, o Estado A seja competente, mas que as partes tenham feito uma convenção em favor de Estado B. A prorrogação, em desacordo com 0 art. 5., è válida tanto para o Estado A quanto para o B, porque os tribunais do Estado A declinaram de sua competência A decisão tomada no Estado B será reconhecida no Estado A. Num caso semelhante. um reconhe vel. Ele é possivel, certamente, para os regimes matrimoniais (art. 58), as sucessōes (art. 96 alinea primeira), os direitos reais imobiliários relativos a imóveis no exterior (art. 108, alinea primeira) e o direito societário (art. 165, alinea primeira, letra "a"). Para todas essas matérias, as decisões tomadas num Estado terceiro e reconhecidas em um Estado competente segundo - Direito suiço podem ser reconhecidas e execu tadas de acordo com a LDIP, pouco importando a autoridade competente em virtude da qual estas decisões foram tomadas. A solução poderia ser entendida, por analogia, a outras questões patrimoniais. Já que ela supõe que exista uma competência indireta estrangeira no Estado $\mathrm{A}$, a questão do art. 59 não se coloca.
2. O Reconhecimento e a Execução, na Suíça, de Uma Decisão Tomada Num Foro

\section{Estrangeiro que Viole Uma Prorrogação em}

Favor de Um Tribunal Suíço

Qual deve ser a solução, no plano do reconhecimento, quando se esta em presença de uma prorrogação validamente concluida e em conformidade com as exigências do art. $5^{\circ}$, no caso de uma parte ter escolhido um tribunal de um Estado estrangeiro que não reconhece a prorrogação quem estatui nesse caso. Suponhamos, por outro lado, que na falta de prorrogação, este Estado fosse competente segundo as regras de competência indireta da lei suiça - na ausência da qual um reconhecimento seria evidentemente excluido.

0 reconhecimento não causa dúvida se 0 defensor procedeu sem fazer reserva. Este caso de competência é previsto pelo art. 26, letra " $c$ ". ${ }^{29}$ Por outro lado, a questão é mais delicada se 0 defensor levantar a declinatória fundamentada na prorrogação e que, apesar disso, o tribuna se declare incompetente.

As soluções das convenções internacionais divergem neste ponto. Segundo o art. 12, Capitulo primeiro, da Convenção sobre o reconhecimento e a execução dos julgamentos estrangeiros em matéria civil e comercial, concluida em Haia em $1^{\circ}$ de fevereiro de 1971 (em vigor em Chipre, nos Paises Baixos e em Portugal, a competência do Tribunal do Estado de origem pode não ser reconhecida quando o Direito do Estado requerido atribui às jurisdições desse Estado uma competência exclusiva, em razão da matéria ou de um acordo entre as partes, para conhecer da ação que deu lugar à decisão estran geira. Este parece ser o único texto no qual se faz expressa alusão à exclusividade decorrente de um acordo entre as partes.

Em contrapartida, vảrias convençōes bilaterais sobre o reconhecimento e a execução concluídas pala Suiça prevêem, sob uma forma ou outra, a possibilidade de recusar o reconhecimento quando o Estado requerido prevê uma competência exclusiva. ${ }^{30}$ Estas regras parecem dever se estender igualmente à competência exclusiva decorrente de uma cláusula de eleição de foro, embora isto não seja um dado muito preciso
Por outro lado, resulta, diversamente do que prescreve 0 art. 28, alinea primeira, da Convenção de Bruxelas e de Lugano, que a violação de uma competência exclusiva, fundada sobre uma cláusula de eleição de foro, não é motivo para recusar-se o reconhecimento.

A doutrina e a jurisprudência se dividem. $\mathrm{Na}$ França, o reconhecimento foi recusado em um caso onde a incompetência não tinha sido levantada. ${ }^{31} \mathrm{Na}$ Alemanha, a opinião contrária parece prevalecer: a eleição de foro não cria uma exclusividade que constitua um obstáculo ao reconhecimento e à execução, mas há igualmente, uma opinião minoritária em sentido contrá rio. ${ }^{32}$

Qual deve ser a solução mediante 0 império da LDIP? Notar-se-á, antes de tudo, que, conforme as convencões bilaterais sobre 0 reconhecimento e a execução citadas acima, poder-se-á sustentar que uma prorrogação de foro de acordo com 0 art. 5o da LDIP cria uma competência exclusiva na Suiça, assim um julgamento ocorrido em um outro pais não deveria ser reconhecido. Em contrapartida, a LDIP, de forma diversa da nova lei turca (art. 38), por exemplo, não prevê, de maneira geral, a existência de um foro suiço como motivo de recusa de reconhecimento. $\dot{\mathrm{E}}$ necessário concluir que os julgamentos provenientes de paises com os quais não existe a convenção têm mais chance de serem reconhecidos? Tal não é o caso se se admite que as convenções bilaterais não impedem as soluções mais liberadas fundadas sobre o Direito comum. Parece-nos que a solução liberal deve prevalecer, ao menos em princípio. Com efeito, a questão dos limites da prorrogação de foro é discutí vel. Pode-se muito bem sustentar que ela deverá ser exclusiva em matéria de contratos de consumidor, de contratos de trabalho, de contratos de seguro e também para outras questões.

Retomemos o exemplo do suiço, proprietário de um apartamento para férias na Itália, alugado a um compatriota domiciliado nos Países Baixos. 0 contrato de locação contém uma eleição de um foro suiço, válida segundo o Direito suiço, mas ineficaz em um pais do Mercado $\mathrm{Co}$ mum em razão do art. xelas, que preve uma competencia exclusiva ao foro da situação. 0 proprietário suiço poderia acionar o locatário no pagamento do alugue 
perante o tribunal suiço escolhido, mas a decisão não poderia ser executada nem na Itália nem nos Paises Baixos. ${ }^{33} 0$ proprietário dirige-se, por conseqüência, ao foro italiano, discutindo em vão, já que o locatário invocarả a declinatória com base na prorrogação de foro. A decisão tomada na Itália poderá ser, certamente, executada nos Paises Baixos, mas o que se passará se, neste meio tempo, o locatário tiver se mudado com armas e bagagens, para a Suiça? Será bem com armas e bagagens, para a Suiça? Será bem
inconveniente ele poder opor-se à execução na Suiça sob o pretexto de que o foro contratual foi violado

Parece-nos que, em tais casos, estando todas as outras condições de reconhecimento e de execuçāo reunidas, dever-se-ia desconsiderar a violação da prorrogação de foro.

Em apoio desta opinião, consideramos, também, que a lei suiça proibe toda revisão dos fundamentos (art. 27, alinea 2); em particular, o feito de que o juiz estrangeiro tenha aplicado uma outra lei não aquela que teria sido aplicada pelo juiz suiço não é motivo de recusa; ou, a atitude mais restritiva de uma ordem juridica estrangeira, em relação a certas eleições de foro, são tão dignas de respeito quanto a regra de conflito estrangeira. Havendo abuso, o reconhecimento podia ser recusado em virtude do art. 27 , letra "b" da lei que sanciona a violação dos principios fundamentais do Direito Processual suíço.

Em conclusão, podemos dizer que a nova lei assegurará a eficácia das prorrogações racionais em favor dos tribunais suicos e, em caso contrário, o respeito à escolha de jurisdições estrangeiras. Ela assegura o reconhecimento das decisões tomadas em foro contratual.

Nosso colega Max Keller, a quem essas linhas são dedicadas, foi o principal artesão das disposiçoes da LDIP sobre a lei aplicável aos contratos. Pareceu-nos apropriado tratar aqui das cláusulas abusivas de eleição de foro que, junto às cláusulas arbitrais, são a contrapartida, no terreno dos conflitos de jurisdiçōes, da autonomia concedida às partes em matéria de escolha da lei aplicável.

\section{NOTAS DE REFERÊNCIA}

1 Eis uma lista das principais publicaçōes sobre 0 tema e as obras de caráter genérico citadas ad Loi fédérale sur le droit international privé (loi de d.i.p.), Projet de loi de la Commission d'experts et Rapport explicatif, Etudes suisses de droit international, vol. 12 Zurique, 1978. Bundesgesetz über das internationale Privatrecht (IPR-Gesetz), Schlussbericht der Expertenkomission zum Gesetzesentwurf, Etudes suisses de droit international, vol. 13, Zuriche, 1979.

Loi fédérale sur le droit international privé, présentation des réponses à la procédure de consultation relative au projet de loi de la Commission d'experts et au rapport explicatif,

Message du Conseil fédéral suisse concernant une loi fédérale sur le droit international privé (loi de DIP) du 10 novembre 1982 (FF 1983 i 255).

Batiffol H. \& Lagarde P. Droit International PriP.ed., tome I, Paris, 1981, tome II, Paris, 1983. Buttent N. \& Moix P.H. La Prorrogation de For Buttent N. \& Moix P.H. La Prorrogation de For
Droit International Privé, Le Juriste Suisse Face au Droit et Aux Jugements Etrangers, Fribourg, p. 315330, 1988.

Fischer C.H. Les Conventions de Prorrogation de for Inter - Et Intercantonales en Droit Fédéral et e Procédure Civile Vaudoise, thèse Lausanne, 1969. Fragistas $\mathrm{N}$. La Compétence Internationale en Droit Privé, Recueil des Cours de l'Academie de Droit International, 1961 III. tome 104, p. 159, spéc. p. 228 (droit suisse) et p. 233 (rôle de la volonté des parties.

Gaudemet-Tallon H. La Prorrogation Volontaire de Juridiction en Droit International Privé, Paris, 1965 Guldener M. Schweizerisches Zivilprozessrech 2.ed. Zurich 1958, avec Suplèment, 1964

Habscheid W.J. Parteivereinbarungen Über die Interenationale Zuständigkeit Nach Deutchem und Schweizerichem Recht, Festschrift Schima, Vienne,
p. 175, 1969.

C. Droit Judiciaire Privé Suisse, 2.ed.
Genève, p. 156, 1981 . Holleaux D., Foyer J., De Geouffre de alle G. Droit International Privé, Paris, 1987. Jayme E. Das europäische Gerichtsstands- und Vollstreckungsübereinkommen und die Drittländer-
Das Beispiel Österreichs, Öst. Akademie der Wissens Das Beispiel Osterreichs, Ost. Akademie der Wissens chaften, Veröffenlichugen der Ko
recht, n. 6, Vienne, p. 97, 1988.

Kaufman-Kohler $\mathrm{G}$. a clause d'élection de for dans le contrats internationaux, Schriftenreihe des
Instituts fur internationales Recht und internationale Beziehungen, Heft 29, Bâle, 1980. Keller M. \& Siehr K. Allgemeine Lehren des Internationalen Privatrechts, Zurich, 1986 Kohler C.H. Pathologisches in EuGVU: Hinkende Gerichtsstandsvereinbarungen Nach Art. 17 Abs. 3 , PRax, p. 340, 1986

Knapp B. L'article 59 de la Constitution, Commentaire de la Constitution fédérale de la Confédération suisse, Bâle, Zurich et Berne, feuillets mobi-

Kropholler J. Internationale Zuständigkeit, chts, Band I, Tübingen 1982, S. 183. insbes. S. 381 chts, Band I, Tübingen 1982,
Rz. 461 ff., S. 495 Rz. $801 f$.

Rz. 461 f., S. Europäisches Zivilprozessrecht, Kommentar zum EuGVU, 3 éd., Heidelberg, 1991. Recht der Zuständigkeitsvereibarung Festschrift fü Heinrich Nagel, p. 157, 1987.

Lalive P. \& Bucher A. Election de domicile et prorrogation de for dans les rapports franco-suisse
La Semaine Judiciaire, p. 297, 1977 .

Mayer P. Droit International Privé 4 ed. Paris,

Poudret J.F. Droit privé fédéral et procédure cantonales: sujet d'êtonnement pour les juristes étrangers et tourments pour les juristes suisses.

Revues Internationale de Droit Comparé, p. 433, 1987. Reiser $\mathrm{H}$. Gerichtsstandsvereinbarungen nach dem IPR-Gesetz. Zugleich ein Beitrag zur Schiedsabrede, Zürcher Studien zum Verfahrensrecht. Band 87, Zürich, 1989 .

Volken P. Von Analogien und ihren Grenzen im internationalen Privatrecht der Schweiz, Festschrif für Frank Vischer, Zürich, S. 335, 1983.

. Neue Entwicklungen im Bereich der internationalen Zuständigkeit, Beiträge zum neuen IPR des Sachen-, Schuld- und Gesellschaftsrechts, de droit international v. 51, Zurich P. 235, 1987. droit International, v. 5l, Zurich, p. 235, 1987 men über die gerichtliche Zuständigkeit und die men uber die garistreckung gerichtlicher Entscheidungen in Vollstreckung gerichtlicher Entscheidungen in Zivil international, v. XLIII, p. 97, 1987. Walder-Bohner H.U. Drei Fragen zum forum rorogatum, Recht und Wirtschaft heute, Festgabe Kummer, Berne, p. 681, 1980.

Zapater Guzman M. La prorrogation de competencia en los contratos de venta concludos por consummidores, Revista española de derecho international, v. XXXIX, p. 447, 1987; résumé en anglais, p. 476.

2 Ver Convenção de Lugano, convenção concernente à competència judiciária e à execução das decisōes em materia civil e comercial, realizada em Lugan em 16 de setembro de 1988, Publicaçóes do Instituto Suiço de Direito Comarado, no 13, I, texto relatório explicativo (texto em inglês, francès, ale- mão e italiano, relatório em inglês e francès) e $\mathrm{n}^{\mathrm{o}}$ 14, II, trabalhos preparatórios, Zurique, 1991. O texto da Convençáa em francess tambem pode se encontrado no "Anuare suisse de droll intemational", vol. XLIV, 1988, p. 166. Ver, ainda, o artigo de P. Volken (citado na nota 1), no "Annuaire suisse de droit international", vol. XLIII, 1987, p. 97. Sobre os principios intertemporais na matéria, ver a decisão do Tribunal Federal, de 29 de novembro de 1990 "Arrêts du Tribunal Fédéral suisse, ATF 116 II 622. Assim, em mais ou menos uma decisão sobre três, tomadas pela Corte das Comunidades sobre a Contratual e a jurisprudencia nacional $\dot{e}$ igualmente fornecida de forma relativa. Ver J. Kropholler e A. Pfeiffer, p. 157, 158, note 4.

4 R. A. Schütze, Zur Ablehnung der Annahme einer Prorrogation nach zürcherichem Recht, IPRax, $p$ III, 1985

Palive \& A. Bucher, p. 300

J. F. Poudret, p. 443 Message no 272 G. Kaufmann-Kohler, p. 161. 0 artigo 17, alinea a, da Convenção de Lugano prevê uma disposição que não figuraria no texto original da Convenção de Bruxelas: "Em matéria de contratos individuais de trabalho as convençōes atributivas de jurisdiçăo produzem seus efeitos se forem posteriores ao surgmento do debate". Este texto foi ainda modificado na Convenção de São Sebastião, relativa à adesão da Espanha e de Portugal à Convenção de Bruxelas, de 26 de maio de 1989; acrescentou-se a esse texto: "ou se o trabalhador o invoca para pedir a tutela jurisdicional junto a outros tribunais que não aquele do domicilio do defensor ou aquele indicado no art. 5.1. Estas divergencias podem ter os efeitos mais inesperados se uma ou outra parte do contrado coula do no plano das decisos ( "matéris patrimoniais", ver: 1. Meier Vermąo de rahtishe patrinons", ver Schlusselberiff Privatrecht (IPRC) Mitteilungen aus dem Institut fü Z vilgerichtlicheș Verfahren in Zurich, Bd. 5, Mai 1988 vilger
S. 5 .
0 artigo

0 artigo 16, alinea primeira, letra "b", da Convenção de Lugano previu que, em matéria de aluguéis de imóveis concluidos em vista de um uso pessoal por periodo máximo de seis meses consecutivos, são igualmente competentes os tribunais do Estado contratante, no qual o defensor é domiciliado, na condição de que o locatário seja uma pessoa fisica que nenhuma das partes esteja domiciliada no Estado contratante onde 0 imóvel esteja situado. Contudo, o Protocolo $\mathrm{n}^{0} 1$ da Convenção, artigo I, permite uma reserva no encontro do reconhecimento da execução de uma tal decisão. A Convenção de São Sebastiâo restringlu esta possibildade exigindo que o proprietário e o locatário sejam pessoas 
fisicas e que sejam domiciliadas no mesmo Estado contratante. Em contrapartida, não há mais possibilidade de reserva.

10 Schröder, loc. cit., supra note 17, p. 534

11 P. 159.

12 Nesse sentido, Fragistas, p. 238

13 O C.P.C. de Zurique, art. II permite, ao contrário, uma cláusula desse gênero (citada supra I, 1)

14 O ante-projeto da Convenção paralela propõe uma fórmula um pouco mais restrita inspirada no art. 9 da Convençāo da Naçōes Unidas sobre os contratos de venda internacional de mercadoril de 1980 (Convenção de Viena).

15 Citado supra, nota 1 . Ele dá conta, sobretudo, da gênese da cláusula e da jurisprudència relativa. Ver igualmente a critica da cláusulas não exclusivas em
H.U. Walder-Bohner, p. 681 .

16 Affaire 22/85, Clunet 1987 p

105, $22 / 85$, Clune 1987 p. 474, IPRax 1987,

105 , Recuel

17 P. 345 e nota 32

18 Bulletin officiel de l'Assemblée fédèrale, mars 1985 . p. 129.

19 Bulletin officiel, septembre 1986, p. 1302.

20 Bulletin officiel, février 1987, p. 976 .

21 EuGVÜ, Nos 68-72, ad art. 17, p. 190

22 No mesmo sentido, o relatório Schlosser, relativo ao texto de 1978, J. O. des Commaunautés européennes. C 59, 5 de março de 1979, no 178; Cf. J. Kropholler, nota 142, p. 191; ver a nota de M.A. Huet relativa à decisáo da Corte de Apelação de Paris de 27 de março de 1987, Journal du Droit International (Clunet), p. 141, 1988

23 Cour de Cassation, $1^{\circ}$ de abril de 1985 , Rivista di Diritto internazionale privato e processuale 1986 , p. 863, e Oberlandesgericht München, 13 de fevereiro de 1985, ibid., p. 931; ver igualmente 0 artigo de S. Mariatti, ibid., p. 819

24 Bulletin officiel, mars 1985, p. 129.

25 Bulletin officiel, septembre 1986, p. 1302.

27 Segundo C.H. Fischer, p. 143
28 Por razōes históricas, os tribunais suiços faziam esse duplo controle no quadro da Convenção FrancoSuica, ab-rogada com efeito $\mathrm{em}^{1}$ de janeiro de 1992; ver C. E. Dubler, La reconnaissance et execution des decisions etrangeres en Suisse. Relatórios suiços apresentados no XII Congresso Internacional de Direito Comparado, Publications de l'Institut suisse de droit comparé, $n^{\circ} 7$, Zurich 1987 , p. 29 , spéc. p. 49.

29 Nesse sentido. C. E. Dubler, op. cit., supra nota 28. Convenção Suiça-Tchecoslováquia, art. 1., Cap. 1.; Convenção Suiça-RFA, art. 1. in fine: Convenção Suiça-ltallia, art. 2., alinea 2 ; Convençăo Suiça-Austria, art. 1., capitulo 1.: Convenção Suiça-Liechtens-
tein, art. $1 .$, in fine.

31 Tribunal de la Seine, 10 janeiro 1962, Revue crittque de droit international prive 1963, p. 607 , note Foyer $G$ de Geouffe de la Pradelle, $n^{2} 966$, 440 Battifol. dacarde II no 718 , note 6 , no mesmo sentido.

32 Ver D. Martiny, Handbuch des internationalen $\mathrm{Zi}$ vilverfahrensrechts, Band III/1, Tübingen 1984, $\mathrm{n}^{\circ}$ 652 e nota 1932, p. 300; ver também Keller/Siehr. p. 580. A opiniáo majoritáia nos foi confirmada pelo professor K. Siehr. No mesmo sentido, 0 art. 32 , alinea 2, du Civil Jurisdiction and Judgments Act, 1982, do Reino Unido.

33 Isto, ao menos, se nos admitirmos, o que parece ser a opiniāo dominante, que os Estados do Mercado Comum tèm a obrigaçao de náo reconhecer a decisáo de um Estado terceiro que viole as regras de foro absolutas do art. 16 da Convenção de Bruxelas, mesmo se este foro for situado em um outro Estado da Comunidade (ver sobre este ponto, Jayme, p. 107 e p. 118, nota 61). Seria diferente se 0 locatário tivesse tido seu domicilio na Alemanha, porque o tratado germano-suiço, de 2 de novembro de 1929 , nào obriga a respeitar a competència exclusiva de um outro Estado e a obrigaçáo de recogacão que ente do art 16, cap primeiro da Convenção de Bruxelas. (Nesse sentido, Kropholler. EuGVŪ, $\mathrm{n}^{0} 20$, ad. art. 25, p. 241).

\section{Imprensa. Captação Audiovisual. Informática e os Direitos da Personalidade*}

ANTÔNIO CHAVES

Professor das Faculdades Metropolitanas Unidas de São Paulo

SUMÁRIO

PARTE I - 1. Imprensa: Jornais, Periódicos; 2. Desgarra-se o Conceito Tradicional de "Imprensa" para o de Informação; 3. Mas Não Apenas a Lei, Como o Próprio Jornalismo Precisa Ser Renovado; 4. Dynabook, o Livro do Futuro; 5. Uma Nova Forma de Editar: CD-ROMs; 6. Fotografias Publicadas pela Imprensa; PARTE II: 7. O Que E Que Se Entende por Captação Audiovisual?; 8. Definição de Obra "Multimidia" ou Eletrônica; 9. O Audiovisua Como Sistema; 10. O Video on Demand (VoD); 11. Internet; 12. A Orientaçãa do Governo; 13. Como Caracterizar uma "Criação" Eletrônica?; PARTE III - 14. A Importância da Programação Cibernética; 15. Uso do Banco de Dados; 16. Imprensa e Informática; 17. Direitos da Personalidade; 18. O Embate Entre a Liberdade de Informação e os Direitos da Personalidade; 19. Limites do Direito de Informação; 20. Divulgaçãa de Fatos Relativos a Persona22. Na Indenização dos Danos Morais Não Mais Prevalece a Tarifa dos arts. 51 e 52 da Lei 5.250/67; Bibliografia.

PARTE I

\section{Imprensa: Jornais, Periódicos}

Não nos permite a amplitude dos assuntos aprofundar o estudo do tema imprensa.

Limitemo-nos a referir que Darcy Arruda Miranda, Comentários à Lei de Imprensa, S. Paulo, Ed. Rev. dos Tribunais, 3.ed., 1995, localiza a madrugada da imprensa nada menos que nos simbolos ou sinais em que, desde a idade da pedra (paleolitica e neolitica) os homens transmitiam os seus pensamentos por meio de incisões e pinturas rupestres.

Já no ano de 1750 a.C., sob o reinado de Thoutmés III, existia um jornal oficial, e ao tempo do Farao Amarsis, jornais satíricos lhe alfinetava a administração. Com Jaques Bourquin, La Liberté de la Presse, 1950, p. 35 registra que na China existiu em Pequim, para mais de 1.300 anos, um jornal: King-Pao.

Os romanos tinham jornais ou atas diurnas que circulavam de maneira regular e, por meio do serviço postal, levavam aos extremos da República ou do Império as novidades de Roma.
No século $\mathrm{XV}$, Veneza enviava aos seus embaixadores e agentes, espalhados pelo mundo, as "fogli d'avizzi", com notícias escritas a mão, dai surgindo a primeira "Gazzetta".

Acompanha a evolução da imprensa no País desde as suas primeiras manifestaçōes, bem como a evolução das leis, até o advento da de n 5.250, de 09-2-1967.

Podemos definir imprensa, no sentido que aqui interessa, como jornal, periódico ou folha noticiosa, e, por extensão, os meios de comunicação em massa escrita ou falada que transmitem noticias e informações.

Garante a Constituição a toda a pessoa, em seu art. $5^{\circ}$, inc. IV: "a livre manifestação do pensamento, sendo vedado o anonimato" e, no inciso $\mathrm{V}$, assegura o direito de resposta "além da indenização por dano material, moral ou à imagem".

0 principio é reiterado, com mais ênfase, no art. 220 , não admitindo $0 \S 1^{\circ}$ que qualquer lei contenha dispositivo que possa constituir embaraço à plena liberdade de informação jornalistica em qualquer veículo de comunicação so- 